\title{
Learning from Scientific Disagreement
}

\section{(Aprendiendo del desacuerdo cientifico)}

\author{
Bruno Borge ${ }^{1 *}$, Nicolás Lo Guercio ${ }^{2}$ \\ ${ }^{1}$ University of Buenos Aires, CONICET \\ ${ }^{2}$ Institute of Philosophical Research (SADAF/CONICET)
}

\begin{abstract}
The article addresses the question of how should scientific peers revise their beliefs (if at all) upon recognized disagreement. After presenting the basics of peer disagreement in sections 1 and 2, we focus, in section 3, on a concrete case of scientific disagreement, to wit, the dispute over the evidential status of randomized control trials in medical practice. The examination of this case motivates the idea that some scientific disagreements permit a steadfast reaction. In section 4, we support this conclusion by providing a normative argument in the same direction; if we are correct, typical reasons for conciliation are absent in this kind of scientific disagreements.
\end{abstract}

KEYWORDS: epistemology; peer disagreement; scientific disagreement; evidence based medicine.

RESUMEN: El artículo aborda la cuestión de cómo deberían los pares cientificos revisar sus creencias (si es que deberian hacerlo) ante el reconocimiento de un desacuerdo. Después de presentar los conceptos básicos del desacuerdo entre pares en las secciones 1 y 2, nos enfocamos, en la sección 3, en un caso concreto de desacuerdo cientifico, a saber, la disputa sobre el estatus evidencial de los ensayos controlados aleatorios en la práctica médica. El examen de este caso motiva la idea de que algunos desacuerdos cientificos permiten una reacción testaruda. En la sección 4, apoyamos esta conclusión proporcionando un argumento normativo en la misma dirección; si estamos en lo cierto, las razones típicas para conciliar están ausentes en este tipo de desacuerdos cientificos.

PALABRAS CLAVE: epistemología; desacuerdo entre pares; desacuerdo científico; medicina basada en evidencia.

* Correspondence to: Bruno Borge. Faculty of Philosophy and Literature, University of Buenos Aires, 480 Puan Street (Buenos Aires, C1406CQJ-Argentina) - brunojborge@gmail.com - https://orcid.org/0000-0002-1755-9690

How to cite: Borge, Bruno; Lo Guercio, Nicolás (2021). "Learning from Scientific Disagreement»; Theoria. An International Journal for Theory, History and Foundations of Science, 36(3), 375-398. (https://doi.org/10.1387/theoria.21967).

Received: 2020-08-23; Final version: 2021-04-19.

ISSN 0495-4548 - eISSN 2171-679X / (C) 2021 UPV/EHU

c) (†) $\odot$ This work is licensed under a

Creative Commons Attribution-NonCommercial-NoDerivatives 4.0 International License 


\section{Introduction}

There is something puzzling about the role of disagreement in scientific practice. On the one hand, the proliferation of rival hypothesis and theories can be thought of as a condition for the growth of scientific knowledge. On the other hand, science seems to be the most suitable area of human activity for the development of stable, long-lasting agreement. ${ }^{1}$ However, this might not be as problematic as it seems. Most scientific disagreements are factual disagreements about propositions we consider to be empirically vulnerable; be they empirical or theoretical disagreements, we can rely on current or future empirical evidence for their resolution. ${ }^{2}$ This is obvious in the former case, and reasons rooted in the empiricist tradition make it plausible in the second, at least for philosophers with realist intuitions. However, this picture of science has been questioned on several grounds, some of them related to the possibility of disagreements that are not empirically decidable (as in cases of underdetermination of theories by the data).

In parallel, disagreement has been thoroughly discussed by epistemologists. Recently, the debate has focused on peer disagreement. The problem can be roughly stated as follows. Consider two subjects, $A$ and $B$, who disagree with respect to a given proposition $\mathrm{P} .{ }^{3}$ In addition, assume that $\mathrm{A}$ and $\mathrm{B}$ are epistemic peers, i.e. they are both cognitive and evidential equals (Lackey, 2010, p. 302). Finally, imagine a situation of full disclosure where both A and $\mathrm{B}$ know that they disagree and that they are epistemic peers. The question then arises: how should A (or B) revise her doxastic attitudes towards $\mathrm{P}$ (if at all) in light of the new evidence? Should A (or B) change her mind after having learned that an epistemic peer disagrees with her regarding some topic? Very roughly, there are two kinds of answers: steadfast views maintain that agents are rationally permitted to retain their doxastic attitudes, while conciliatory views contend that they should significantly modified their opinions. ${ }^{4}$

In this article, we aim at connecting both debates, in the hope that a close examination of the nature of scientific disagreements will bring light into the dispute over peer disagreement. More specifically, we present and characterize, through a concrete example, a specific kind of scientific disagreements, namely disagreements between scientists having different fundamental epistemic perspectives, and we provide a normative argument for a steadfast

1 Although some radical anti-realist views on science question the existence of stable agreement through the history of science.

2 This claim becomes highly controversial in the case of formal sciences. Consider mathematics. First, not everybody would agree on characterizing mathematical disagreements as factual. Second, even among the ones who do think that mathematical disagreements are factual (say, Millian empiricists and platonists), there is no consensus about mathematical propositions being empirically vulnerable. And the same runs for logic, perhaps with extra complications. For these reasons, our characterization of scientific disagreement is focused on natural and social sciences, even when we believe the framework that we put forward in this article can account for disagreements in formal sciences too.

3 We set aside disagreements concerning evaluative matters, a topic that has been the subject of intensive debate within philosophy of language in recent years. For an interesting discussion of the connection between the two debates see Carter (2014).

4 There are other possibilities. Kelly (2010) defends the Total Evidence View, according to which one should answer the aforementioned questions on a case by case basis depending on the import of one's total evidence. For his part, Christensen (2010) maintains that these situations generate an epistemic dilemma where neither answer is completely satisfactory, for both fall short of some rational ideal. 
view. The article is structured as follows: in the next section we discuss peer disagreement. After presenting what we take to be the main motivation for adopting a conciliatory view, we lay out two standard arguments in its favor. In addition, we discuss some assumptions often made within the epistemological debate over peer disagreement and we compare our own way of framing the debate on these issues with some recent alternative proposals. In section 3, we turn to scientific disagreement. We focus on a concrete case in order to motivate the idea that some scientific disagreements permit a steadfast reaction. Finally, in section 4, we provide a normative argument in favor of this view, by showing that in the relevant cases standard reasons for conciliation are absent.

\section{Peer disagreement}

\subsection{The ARGUMENT FOR CONCILIATIONISM}

As we said, there are mainly two types of views on peer disagreement. Conciliatory views maintain that peer disagreement always prescribes a significant degree of doxastic revision. According to steadfast views, in turn, there are circumstances in which one is rationally allowed to retain one's attitude in the face of peer disagreement. In a nutshell, the main thrust behind conciliationism is that recognized peer disagreement provides the subject defeating higher-order evidence (viz. evidence concerning the existence or the import of first-order evidence) that her original evaluation of the first-order evidence is mistaken. ${ }^{5}$ As a consequence, she ought to reduce the level of confidence in her belief or, alternatively, suspend judgment on the matter.

There are at least two different ways of implementing this basic idea. One might think of epistemic peerhood in terms of rationality: on this view, an epistemic peer is "one whose opinion is equally likely to be rational” (Christensen, 2016, p. 586). Alternatively, one might characterize epistemic peerhood in terms of accuracy. Thus understood, an epistemic peer is "one whose opinion on the disputed issue one expects to be as likely to be accurate as one's own” (Christensen, 2016, p. 586). Each view makes for a different argument in favor of conciliationism.

If one takes the first option, the basic conciliationist insight can be restated as follows: disagreement with an epistemic peer constitutes higher-order evidence that the agent's original evaluation of her first-order evidence was irrational, hence she ought to revise her original attitude. The conclusion relies upon some assumptions. The first one was already noted: prima facie, the agent is not justified in believing that her opponent is more likely than her to have formed an irrational belief, since they are epistemic peers. The second one is that in assessing the likelihood of her peer having formed a rational belief the agent ought not rely upon her own reasoning on the disputed matter. This requirement is known as the principle of Independence:

5 There is a difference between typical undercutting defeaters and the kind of defeating that is presumably going on in cases of peer disagreement. An undercutting defeater is evidence that, once added to your original evidence, turns your previously rational belief irrational. By contrast, peer disagreement provides higher-order evidence that that your original belief was not rational to begin with (cf. Lasonen-Aarnio (2014)). 
Independence In evaluating the epistemic credentials of another person's belief about $P$, to determine how (if at all) to modify one's own belief about $\mathrm{P}$, one should do so in a way that is independent of the reasoning behind one's own initial belief about P. (Christensen, 2009, p. 758)

The third assumption consist in the idea that the evidence supports one doxastic attitude toward the propositions under question. This thesis is known as Evidential Uniqueness:

Evidential Uniqueness Necessarily, for any proposition $\mathrm{P}$ and body of evidence $\mathrm{E}$, there is some doxastic attitude $\mathrm{D}$ such that, for any subject $S$, if $\mathrm{E}$ is $S$ 's total evidence, then it is rational for $\mathrm{S}$ to have $\mathrm{D}$ towards $\mathrm{P}$ and irrational for $\mathrm{S}$ to have any contrary doxastic attitude toward $\mathrm{P}$. (Lee, 2013, p. 164)

First, Evidential Uniqueness implies that in a case of peer disagreement the opponents cannot both have equally rational beliefs. Second, since they are peers, each one is as likely to be rational as the other. Finally, by Independence neither can rely upon her own reasoning in order to evaluate whether it is her rival who has formed an irrational attitude. Given all of this, each agent has higher-order evidence that maybe it is her who made a mistake, and this evidence defeats her initial belief. Hence, they must conciliate. ${ }^{6,7}$

Let's turn to the second alternative. An argument in this line is provided by Cohen (2013). He argues that after learning of the existence of a peer disagreement the agent obtains evidence that there is an alternative rational line of reasoning that leads to a different conclusion. If we grant to the steadfast that Evidential and Doxastic Uniqueness are false (or at least very controversial), this fact does not constitute evidence that her belief is irrational. However, Cohen argues, it still constitutes evidence that her belief is inaccurate, since she cannot assume that her peer's alternative reasoning is less accurate than her own. This evidence functions similarly to a rebutting defeater, although for graded beliefs. ${ }^{8}$ So even if the agent does not have evidence that her belief is irrational,

6 As Ballantyne \& Coffman (2012) and Lee (2013) have shown, Evidential Uniqueness is sufficient but not necessary for the argument. Conciliationism can be secured by adopting the thesis that agents cannot know that a body of evidence is permissive while believing one of the attitudes that the evidence permits. Cohen makes a similar point, relying on what he calls Doxastic Uniqueness:

Doxastic Uniqueness A subject cannot rationally believe there are two (or more) rational credences [or doxastic attitudes] for [a hypothesis] $\mathrm{H}$ on [the evidence] $\mathrm{E}$, while rationally holding either. (Cohen, 2013, p. 101)

However, Ballantyne and Cofmann show that rejecting Evidential Uniqueness while maintaining that agents cannot know that the evidence is permissive results in a very controversial and unintuitive view. Something analogous could be said of the view that results by substituting Doxastic Uniqueness for Evidential Uniqueness, unless it is supplemented by an additional argument, as Cohen does (see discussion below).

7 In order to block the argument some defenders of the steadfast view reject Evidential Uniqueness in favor of a permissive account of evidence (Douven (2009); Kelly (2010, 2013)), while others argue against Independence (Lackey (2010, 2013); Pittard (2019); Sosa (2010)). Our view aligns with the latter group (see section 4 below).

8 Cohen relies on Joyce's [1998] account of accuracy: when $S$ assigns the level of confidence $n$ to $P$ (given $0 \leq n \leq 1$ ) the accuracy of S's doxastic attitude equals $n$ if $\mathrm{P}$ is true, and $1-n$ if it is false. 
there is rational pressure related to the accuracy of her belief for her to conciliate. Crucially, Cohen's argument does not appeal to Evidential or Doxastic Uniqueness, but it does require Independence: were the agent justified in relying upon her own reasoning in evaluating the epistemic credentials of her peer's belief, remaining steadfast would be legitimate for her.

Now, in both kinds of argument the basic strategy is the same, namely to show that higher-order evidence from recognized peer disagreement constitutes a defeater for the subject's original belief. It might be higher-order evidence that her belief is irrational or that it is inaccurate. In the former case, Evidential (or Doxastic) Uniqueness and Independence are needed. In the latter, only Independence is required. As we will see in the next sections, however, these arguments can be blocked in some cases of scientific disagreements.

\subsection{Framing the Debate}

In the recent literature, several efforts have been made to connect the epistemological debate over peer disagreement with the problem of scientific disagreement (see Straßer et al. (2015); Ššelja (2019); de Donato Rodríguez \& Zamora Bonilla (2014); Lichtenstein (2020); Kelp \& Douven (2012); Elgin (2010); De Cruz \& De Smedt (2013)). Before moving on, it is worth pausing to highlight some important differences between our own approach and some of these views.

The debate over peer disagreement aims at answering the question, what does epistemic rationality require of an agent in the face of recognized disagreement with an epistemic peer? However, thus formulated the question could be understood in different ways, in relation to at least three different issues. The first one concerns the difference between the synchronic and the diachronic dimensions of epistemic rationality. Synchronic epistemic rationality concerns the mental states (we focus on beliefs or credences) that best fit an agent's general epistemic situation at a given time. So, the synchronic question about peer disagreement concerns the beliefs or credences that are rationally required or permitted for a subject given her current epistemic standing, including higher-order evidence stemming from peer disagreement. Diachronic epistemic rationality, in turn, is about the epistemic performance of an individual over time; in effect, some attitudes may be epistemically rational not because they are supported by the present evidence of the subject, but because they are expected to improve her epistemic standing in the future. So, the diachronic question about peer disagreement concerns the best response to recognized peer disagreement in the long run.

To see the point, consider the views of Kelp \& Douven (2012) and Straßer et al. (2015). These approaches are diachronic in nature. Kelp and Douven adopt a dynamic approach, on which disagreement is taken to be a process involving successive rounds of deliberation and disclosure. They maintain that scientists in a peer disagreement situation are justified in retaining their beliefs during the process, in so far as they commit to critically engage with the opposite view, and to suspend judgment if they cannot refute it. Kelp and Douven contend that remaining steadfast preserves variability of judgment, which is valuable for scientific investigation, for it lowers the probability that every scientist ignores or dismisses relevant evidence, or that some theories or hypotheses are prematurely discarded. For their part, Straßer et al. (2015) argue for epistemic tolerance in the face of peer disa- 
greement. Epistemic tolerance is required when the agent finds the opponent's view objectionable but still admissible, since there are indices that it is the result of rational deliberation. In the same vein as Kelp and Douven, Straßer et al. argue that the tension that tolerance sustains (between one's assessment of the opponent's view as incorrect and one's admission of her position as potentially rational) is epistemically motivated because it prevents the premature dismissal of certain theories and it forces both parties in the debate to seek further evidence and arguments, to find inconsistencies on the rival's views, etc., which may lead to the closure of the debate. Crucially, both views make appeals to prospective reasons. Maintaining variability of judgment, avoiding premature dismissal of rival theories, and critically engaging with incompatible theories do not concern what are the required beliefs or credences for an agent at a certain time given her total epistemic situation, but what is best for inquiry in the long run.

The second issue worth discussing has to do with the kind of attitude ascribed to participants in the disagreement. Within the epistemological debate over peer disagreement, it is often assumed that the agents (dis)believe or suspend judgment on a given proposition, or alternatively, that they assign some credence to it, that is, that they have a certain degree of confidence in such proposition. However, one may phrase the problem in terms of another kind of attitude. Elgin (2010), for example, argues that we should phrase the debate in terms of acceptance instead of belief. This is a substantive difference, because while belief is arguably involuntary, acceptance (the commitment to treat certain proposition as a premise for inference or as the basis for action) is not; it is, in turn, an action one decides (or not) to perform. One could also make appeal to other kind of attitudes, like those identified by Lacey (2015) within different stages of scientific practice (holding, adopting, endorsing).

In order to introduce the third and final issue we want to highlight, it will be helpful to briefly comment on Fleisher's [2020] view. Fleisher points out that scientists often adopt an attitude of committed advocacy towards a theory despite the fact that widespread peer disagreement (or some other factors) makes it irrational for them to believe (or have a high credence) on such theory. In order to account for the rationality of scientists in those situations, he proposes to recognize the attitude of endorsement. ${ }^{9}$ Endorsement is sensible to extrinsic epistemic reasons. These reasons need not be reasons to believe that a theory is true (for example, testability may be an extrinsic reason to endorse an hypothesis) and, crucially, they need not concern the epistemic performance of an individual agent but the promotion of healthy collective inquiry. Thus, as Fleisher points out, "there is thus a tension between our theory of individual epistemic rationality, and the goals of collective inquiry" (Fleisher, 2020 , p. 10). ${ }^{10}$ The same tension can be found when asking about the the most rational response to scientific peer disagreement: one may focus on what is best in terms of individual epistemic rationality or, alternatively on what is best for the goals of collective inquiry.

The previous discussion makes it clear that it is possible to approach the question of peer disagreement from different angles, that is, by focusing on different dimensions or facets of epistemic rationality. On the one hand, one may concentrate on attitudes like acceptance, endorsement, etc., and ask what is the most epistemically rational course of action in order to promote healthy collective inquiry in the long run. On the other hand, one may be

9 To be differentiated from Lacey's [2015] notion of endorsement.

10 See also Šešelja $(2019$, \$3.3). 
interested in what beliefs or credences are rationally required or permitted for an individual in virtue of her current epistemic situation. These questions are conceptually distinct and their answers seem to be somewhat independent. For example, endorsing a theory (in Fleisher's terms) in the face of peer disagreement is compatible with being conciliatory: a scientist might be conciliatory w.r.t. her beliefs on a given hypothesis while continuing endorsing it, for she thinks that this will better promote the goals of collective inquiry. Likewise, admitting the rival's view as potentially rational (in Straßer et al.'s terms) is compatible with scientists being steadfast: the latter implies retaining her belief, while the former means that she tolerates her rival's view. We do not consider these approaches to be mutually exclusive, they just point to different dimensions on which we evaluate epistemic rationality. We believe that both kinds of questions raise important and interesting epistemological issues and are worth pursuing. In this article, however, we take an individual, synchronic approach to the question, in line with most of the literature on peer disagreement. Within that framework, we will argue that some scientific disagreements exhibit characteristics that make it rational for the parties to remain steadfast. The previous discussion serves to make explicit the framework within which we are working as well as the limits of our argument.

\section{Disagreement in science}

As described by epistemologists, peer disagreement presupposes notions such as epistemic peer, shared evidence, evidential support, and more. Most of them are just idealizations, theoretically construed to analyze and test intuitions about disagreement as a general phenomenon. Now, one might worry that these idealized notions cannot provide information about such a complex phenomenon as disagreement in science. Determining what is the total evidence in favor or against a scientific proposition is often a hard issue, and it is highly unlikely that two agents share exactly the same evidence, even in seemingly unproblematic contexts such as disagreements over basic empirical propositions like 'this apple is red'. However, we believe that those idealizations have a role in providing knowledge about general features of disagreement analogous to that of idealized models in some sciences. Although important details are in dispute, it is commonly accepted that an idealized model can provide knowledge about its target if it "captures" some of its relevant (structural and/ or qualitative) features. Likewise, working with the above mentioned idealizations can bring light over some interesting properties of disagreement and deepen our general understanding of the phenomenon. Having said that, science seems to be, among the areas of human activity, a great domain to look for instances of the idealized notions of epistemic peer, shared evidence, evidential support, and, of course, peer disagreement. If that is the case, considering the particularities of scientific disagreement could be very helpful to inform epistemologists' current notions and to motivate new ones. ${ }^{11}$ In this section, we attempt to show

11 It worth noting that there are also methodological advantages associated with assuming cognitive and evidential parity in scientific practice. On the contrary, if one regards oneself as epistemically inferior/ superior to others then one may defer to their claims with less scrutiny or reflection then may be appropriate in some cases, or overlook important reasons for an alternative point of view. 
some of the relevant features of scientific disagreement in what we call The Weight of the Evidence Case. Then, we provide an example of an instance of that case in scientific practice.

\subsection{A QUiCK LOOK INTO THE NATURE OF SCIENTIFIC DISAGREEMENT}

Disagreement is undoubtedly a moving force for science. The proliferation (and elimination) of rival theories or hypothesis about the same natural phenomenon is an essential part of the development of scientific knowledge. For that reason, scientific disagreement attracted the attention of many philosophers of science, who engaged in debates about the confirmation and refutation of theories and processes of theory choice. In some contexts, stable agreement was called into question. The historicist philosophy of science, for example, focused on the ontological discontinuity through theory change and the radical shifts in the scientific image of the world. Considerations about the semantics of theoretical terms and the theory-ladenness of observational evidence were cited as reasons to undermine the possibility of stable, long-lasting agreement in science (cf. Hanson (1958); Kuhn (1962)).

Leaving aside their philosophical merits, these views neglect the very general and widely accepted intuition that science is essentially a matter of agreement (stable and generalized agreement seems to be more frequent in modern scientific enterprise than in any other human social activity -e.g. politics, religion, philosophy, art, etc.), a common sense claim that finds support in some philosophical approaches to science such as scientific realism, with its view of scientific knowledge as continuous and cumulative. ${ }^{12} \mathrm{On}$ this view, the empirical sciences lie close to the formal sciences, where the preeminence of stable agreement is often thought to be indisputable. ${ }^{13}$

Admitting, on the one hand, that disagreement is one of the moving forces for science, and, on the other hand, that there is a preeminence of stable agreement in scientific practice, suggests that scientists tend to conciliate when facing peer disagreement. Plausibly, in real life examples scientists hardly ever conciliate by "splitting the difference," or by proportionally lowering their initial credence in the proposition under dispute. Many cases of scientific peer disagreement are solved by exposing some deficiencies in the way the other party analyzed or interpreted the evidence (which, properly done, is coherent with Independence). When there is no reason to think that that is the case, the usual strategy for dissolving scientific disagreement is looking for new evidence. This is, in fact, how most scientific controversies are resolved. However, even if this is not a proper conciliatory solution in the previously specified sense, arguably the mere act of recognizing that more evidence is needed is a sign of a variation in the initial doxastic attitude towards a proposition. A good example of this kind of situation is given by crucial experiments, that is, experiments capable of decisively determining whether or not a particular hypothesis or theory is superior to

12 Although the common sense intuition is stronger than the realist commitment since the former (unlike the latter) does not require the subject of the agreement to be true (or approximately true) propositions.

${ }^{13}$ See Kornblith (2010, p. 42). 
all rival hypotheses or theories, ruling out all alternatives except the experimenter's hypothesis.

The remarks above suggest that scientists tend to conciliate when facing peer disagreement. Against this preliminary intuition, we will provide reasons to support a steadfast view on scientific peer disagreements, based in part on a new understanding of the latter. The steadfast view we defend is only committed to the idea that some peer disagreements allow the agent to retain her opinion, so it is consistent with conciliationism being the rational response on many occasions.

There are kinds of scientific disagreement that make good candidates for a steadfast reaction. First, consider the widely discussed cases of underdetermination of the theory by the evidence. We already noted the role that crucial experiments play in science: when the available evidence does not suffice to decide between two rival theories, crucial experiments provide new evidence capable of motivating a decision. But, what happens if no addition of new evidence could break the impasse, as in cases of underdetermination? This cases seem to constitute a peer disagreement in which rival scientists could not appeal to new evidence to decide the disagreement. Now, the usual way to motivate theory choice between empirical equivalents is to take non-empirical virtues into account, such as simplicity, parsimony, explanatory power, or even more aesthetic-sounding virtues, such as elegance or beauty. Then, in the light of the same evidence, two agents could take different doxastic attitudes towards a hypothesis (say, belief and rejection) based, ultimately, not on differences in the evaluation of such evidence, but on the fact of having divergent hierarchies of non-empirical virtues: e.g. one of them might prefer a rival hypothesis because she considers parsimony to be preferable over explanatory power. ${ }^{14}$ Crucially, one might think that there is not a uniquely rational way of weighting non-empirical virtues. If this is correct, the cases are such that: (a) scientists share all the available evidence; (b) they are peers; (c) they rationally assess the evidence; but (d) they still disagree on their doxastic attitude towards a theory or hypothesis. So, underdetermination cases provide examples of reasonable steadfast reactions upon disagreement.

A second kind of cases can also be found in the literature. Following Junges (2013), we can call it perspective of access cases. The model pluralist position concerning the units of selection debate in biology (Boucher, 2014), the anthropological debate over the existence of cannibalistic practices (Salmon, 2000) and the debate around the theory of continental drift (Lugg, 1980; Solomon, 1992) are instances of this type. Observing the interdisciplinary nature of the controversy on continental drift, for example, Junges maintains that what explains the disagreement is that each specialist gave a little more weight to the evidence coming from his field of study, considering it of greater relevance:

Thus, it is the perspective of access what explains why, at the beginning of 1960 , paleomagnetists were convinced that their data conformed to mobilism, while continental geologists re-

${ }^{14}$ Laudan \& Leplin (1991, p. 462) argued that the evidence for a hypothesis could exceed its empirical consequences. For example, being compatible with or deducible from a more general well-established theory should be regarded as evidence in favor a given hypothesis. This view is controversial, but even if correct, it cannot be plausibly extended to other non-empirical virtues: the simplicity of a hypothesis, for example, cannot be counted as evidence in its favor. Thus, there is still room for evidential equivalence. 
mained 'skeptical' about it. Consensus only began to emerge as data from each specialty conformed to the continental drift hypothesis. (Junges, 2013, p. 626) (Our translation)

Differences in what he calls perspective of access to the evidence are not performance errors or irrational stands of the agents in relation to the evidence. They seem to be rationally admissible discrepancies in the norms or policies regulating their belief-forming practices. Again, this type of case seems prima facie like a good candidate for advancing a steadfast view.

There is a third promising kind of disagreement, on which we want to focus in this article to make a case in support of a steadfast view. This is a kind of case in which scientists share evidence and are cognitive equals, but they diverge in what we will call epistemic perspective (more on this notion in section 4.1). ${ }^{15}$ As De Cruz \& De Smedt (2013, p. 171) put it, "In such cases, parties have the same epistemic goals, but they disagree on which epistemic principles should be used to achieve them." In the next subsection, we present a concrete instance of this kind of case, and in section 4 we argue that it allows for a steadfast reaction.

To sum up, here is a general sketch of the kind of scientific disagreement we believe motivates a case against the conciliatory view.

The Weight of the Evidence Case (WEC): agents $S$ and T are in a peer disagreement situation regarding a proposition $\mathrm{P}$, given evidence $\mathrm{E}$. They both (correctly) assessed $\mathrm{E}$ in the best way possible. But, while $S$ judges that $E$ is enough evidence for believing that $P, T$ judges that $E$ is not enough evidence for believing that $\mathrm{P}$, so she takes a different doxastic attitude towards $\mathrm{P}$ (e.g., she remains agnostic about it).

\subsection{An instance of WeC: Evidence-Based Medicine}

Evidence-Based Medicine (EBM) appeared in the early nineties as a novel approach to clinical decision-making processes, with great success. It was even regarded as a new Kuhnian paradigm in its field (Group, 1992). The very definition of EBM is a widely discussed issue, but its core claim concerns the hierarchy of evidence in favor of a treatment or intervention: all EBM's proposed hierarchies give priority to Randomized Controlled Trials (RCT) over observational studies, mechanistic reasoning, and expert judgment (cf. Burns et al. (2011)). Like observational studies, RCTs are a form of comparative clinical studies. The main idea behind this kind of study is to determine the efficacy of an intervention, e.g. an experimental treatment, comparing (at least) two groups of patients, one that receives the intervention and another "control" group that receives a different (standard) treatment or a placebo. Significant differences in the outcomes of the compared

15 Although we will not argue for this point here, we believe that cases of disagreement motivated by underdetermination and differences in the perspectives of access are ultimately variations of disagreements arising from the adoption of conflicting epistemic perspectives. Field-based variation in norms and epistemic policies, as well as variation as to non-empirical virtues of theories seem like prime candidates for differentiating the kind of belief formation framework that we label as the epistemic perspectives of agents. We thank an anonymous reviewer for calling our attention to this point. 
groups are taken as evidence of the effectiveness of the treatment, that is, the study is interpreted as evidence for a causal relationship between the intervention and the outcome. In observational studies, the comparison is made by considering only records of (similar) patients that receive the standard and the experimental treatment. However, their respective allocation corresponds to the clinical decision of their doctors. In RCTs, on the other hand, the allocation to receive the experimental intervention or a control is totally randomized. This is supposed to rule out self-selection and allocation biases, that is, the systematic intervention of confounding factors (i.e. those that can undermine the feasibility of the experimental outcome) arising from the greater probability of one specific group (e.g. elderly patients) to prefer the experimental treatment or be allocated to receive it by their doctors. Moreover, randomization allegedly neutralizes all confounders, both known and unknown (Sackett et al., 2000). In part for those reasons, EBM's principles are thought to provide "gold standard" evidence for the effectiveness of a clinical intervention (Timmermans \& Berg, 2003).

There are, of course, many detractors to EBM. Their general attacks are often directed at (but not limited to) the following points: first, randomization is not essential for quality experimental evidence in medicine (Worrall, 2007a). Second, confounders are effectively eliminated only in large numbers, and RCTs are usually not conducted with large groups of patients (Worrall, 2002). Third, EBM does not account for the problem of external validity, that is, the problem of how to extrapolate the claims about the efficacy of a treatment within the experimental group to the general population (Cartwright, 2011; La Caze, 2011). In fact, according to Worrall (2002, 2007a,b), of all the alleged advantages of RCTs, only the control of allocation biases stands up to scrutiny.

Besides being the preferred form of comparative studies, RCTs are, according to EBM, a much better source of evidential support than mechanistic reasoning and expert judgment. So, a simplified EBM hierarchy of evidence should look like this (in every case, systematic reviews of studies are assumed to be superior to single studies): (i) RCTs, (ii) observational studies, (iii) mechanistic reasoning, and (iv) expert judgment. Having said that, for reasons of space we will focus on EBM's claim that RCTs provide better evidence than mechanistic reasoning, and in the main arguments for and against that claim.

An interesting way to capture the idea behind mechanistic reasoning is to compare it with RCTs. In the latter (as in any comparative clinical study), the specific causal chain linking the intervention with the experimental outcome is, as far as the study is concerned, a "black box": all that matters is the correlation of the intervention and the outcome in the relevant circumstances. In contrast, mechanistic reasoning requires opening the box, that is, identifying the relevant mechanism activated by the intervention that leads to the outcome. There are many definitions of what a mechanism is (see Craver \& Tabery (2015)), but most of them consider mechanisms as specific arrangements/organizations of parts/features that lead to regular or stable relationships between "inputs" and "outputs". On these views, mechanistic reasoning is an inference from knowledge of the mechanisms activated by a specific intervention to certain expected outcome. There is, of course, much more to be said about mechanisms and mechanistic reasoning, but this suffices for our present purposes. It is also worth noting that mechanistic reasoning is closely related to mechanistic explanation. In this context, the resulting experimental outcome is explained in terms of the relevant mechanism, which details what goes on inside RCT's black box. 
There are many arguments for and against EBM's claim about the superiority of RCT over mechanistic reasoning. The most philosophically interesting defenses of EBM's hierarchy point out alleged deficiencies in mechanistic reasoning. Most of them are epistemological concerns. First, it is argued that knowledge of the (psychological, pathological, biological, etc.) mechanisms intervening in clinical response to treatment is ussually limited: some mechanisms are unknown, and those effectively identified are often only partially understood (Howick, 2011). A second problem is that the mechanisms involved in clinical responses are always part of a progressively more comprehensive system of mechanisms operating in lower or higher levels of fundamentality, but the precise way in which they affect/ constraint the relevant mechanisms in a mechanistic explanation is usually very hard to determine. Finally, metaphysical concerns about the stochastic nature of some mechanisms have also been raised (see Howick (2011)).

On the other hand, many argue against the superiority of RCTs over mechanistic reasoning. Usually, they claim that both are complementary and equally good sources of evidence. Besides all the referred objections to the reliability of RTCs, the preferred line of defense of mechanistic reasoning relies on the difference between causation and mere correlation:

\footnotetext{
It is a truism that correlation is not causation, but attempts to spell out what distinguishes causal correlations from accidental ones have not been particularly successful. MTC [mechanical theory of causation] meets this deficiency by requiring that two events are causally related if and only if those events are connected by a mechanism. (Glennan, 1997, p. 509)
}

This is the idea behind the so-called Russo-Williamson Thesis: both mechanistic reasoning and RCT are needed to establish causal claims, because "if there is no plausible mechanism from C to E, then any correlation is likely to be spurious" (Russo \& Williamson, 2007, p. 159). They offer both historical and theoretical support for this thesis. It is also advocated by Gillies (2010) in the case of the claim that smoking causes heart disease. A similar point was made by Cartwright \& Munro (2010) in relation to the problem of external validity.

Arguments for and against EBM's claim about the superiority of RCTs over mechanistic reasoning show many complexities, but we take the demand of explanation to be the central issue at stake. While EBMers believe that a well established experimental correlation is enough evidence for the effectiveness of an intervention, advocates of mechanistic reasoning hold that a more or less precise account of the relevant mechanisms involved in the causal connection between the intervention and the experimental outcome is required for the correlation to count as good evidence. They demand a mechanistic explanation of what is inside RCT's black box. For that reason, despite the arguments from both sides being empirically informed, the problem does not seem to have a definitive empirical (or empirically informed) solution. Even the best-established correlation (by an RCT meeting a set of preferred standards) could be seen as sufficient evidence for a causal claim (related with the effectiveness of a clinical intervention) by an EBMer, and as insufficient evidence for believing the same claim by an advocate of the Russo-Williamson Thesis. Thus, they would form different doxastic attitudes towards a proposition that maintains a given intervention is effective (say, one of them believe it while the other suspends her judgment), given the same body of 
evidence. We only need to assume they are epistemic peers that (correctly) assessed the evidence in the best way possible to have an instance of The Weight of the Evidence Case.

\subsection{SCIENTIFIC AND META-SCIENTIFIC DisagREEMENT}

We have presented the EBM case as an instance of WEC, that is, as an example of how a variation in epistemic perspective renders a steadfast response to a scientific dispute reasonable. However, some might worry about this being a case of metascientific disagreement in the philosophy of science instead of a disagreement about first-order scientific facts. A possible reason for this worry could be that what motivates the disagreement seems to be a philosophical difference regarding the value of explanation. It would be of no help to point out that this is a factual disagreement, given that many meta-scientific disagreements are factual as well. We will not discuss meta-scientific disagreement in this paper (we have examined disagreements about scientific ontology in Borge (2021)). However, we present in this section reasons for regarding the EBM case as one of scientific disagreement.

For a start, the disagreement in the EBM case does not have two usual and distinctive features of meta-scientific disagreements. First, disagreements of this kind are about philosophical questions regarding science (or at least some aspect of it) as an epistemic enterprise: its aims, commitments, methods, and/or epistemic power. Second, meta-scientific disagreements usually do not have significant impact in the way scientists work in the laboratory. Consider the dispute about scientific realism. The debate confronts (among other contenders) standard scientific realists (who believe that the unobservable entities postulated by our best scientific theories exist) with constructive empiricists, who maintain that reliable scientific knowledge is limited to what theories say about the observable phenomena. In this case, the disagreement concerns scientific ontology (endorsement or rejection of existence claims about unobservable entities such as electrons), the aim of science (approximate truth or empirical adequacy), the reliability of Inference to the Best Explanation, and the type of knowledge we can reasonably expect to get from science (knowledge about both the observable and unobservable parts of the world, or just about the former). Additionally, disputes about scientific realism have little or no impact in the laboratory life. Two scientists can work in exactly the same way using Coulomb's law to design an experiment, even if they disagree about the degree of ontological commitment that should be assumed towards electrostatic force, natural necessity, or the law itself. By contrast, the target of the disagreement in the EBM case is a proposition about an object of scientific inquiry (i.e. the efficacy of a specific medical intervention) and not about the aims, commitments, or epistemic features of science itself. Moreover, unlike what happens in cases of meta-scientific disagreement, the disagreement about a causal claim backing the efficacy of an intervention has direct and relevant consequences in scientific practice.

Nonetheless, we acknowledge that deciding when a proposition in dispute is about a first-order scientific fact or about a meta-scientific issue is not always a straightforward task. Sometimes, the line between scientific and meta-scientific disagreement is blurry, and it is reasonable to think that the distinction is a matter of degree. There 
are paradigmatic cases of the two types of disagreement, but there may be cases in which both scientific and meta-scientific matters are jointly at issue. For the reasons given above, we think the disagreement in the EBM example is not one of them. But even if we are wrong, the fact that first-order scientific facts and meta-scientific issues are together at stake in a dispute does not necessarily mean that we should treat it simply as a meta-scientific disagreement in the philosophy of science. Weinberger and Bradley have shown that many well known examples of scientific disagreements derive from "broader methodological or foundational differences between the communities" [2020, p. 43]. However, the authors emphasize the scientific character of these disputes, and recommend being "skeptical of any claim that scientific debates can be traced back to debates between proponents of different philosophical theories" [2020, p. 41].

\section{How to be steadfast}

In section 3, we described The weight of the evidence case (WEC), that we distinguished from typical cases of scientific disagreement in which the dispute is solved by seeking further evidence. We showed that in WECs scientists frequently remain steadfast, and we tried to motivate this idea by presenting the EBM case, which we believe prompts the desired intuitions. In this section, we will strengthen the case by providing a normative argument in support of our view.

\subsection{EPISTEMiC PERSPECTIVES}

Our discussion of WECs in 3 made it clear that when assessing the rationality of rival hypothesis scientists take into account not only evidence, which not always suffices to settle the issue, but also several theoretical values (hierarchically ordered according to their preferences) as well as different stances concerning the status of different types of facts as evidence, the relative weight of various kinds of evidence and maybe some privileged epistemic goals. ${ }^{16} \mathrm{We}$ refer to this set of epistemic policies as the epistemic perspective of a subject. Thus, an epistemic perspective in the present sense consists in a policy for forming beliefs, more specifically, a policy for determining the rational doxastic attitude towards a proposition as a function of the features previously mentioned.

Given the importance that the notion of shared epistemic perspective will have in the rest of this work, it will be helpful to specify the conditions under which two agents hold the same epistemic perspective.

Shared epistemic perspective Two agents $S$ and T hold the same epistemic perspective when they (a) pursuit the same epistemic goals, (b) embrace the same hierarchy of values as the most adequate for achieving their epistemic goals, and (as a result of that) (c) share the same epistemic policies for determining the maximally rational doxastic attitude to take towards a

16 The precise relationship between a hierarchy of values and the achievement of epistemic goals is a complex issue that falls beyond the limits of this work. 
proposition (as a function of the available evidence, the hierarchy of values, and the preferred epistemic goals).

In addition, we make two assumptions about epistemic perspectives. Our first assumption is about the best way of representing the interaction between the different epistemic perspectives of a subject. In this regard, we assume that some epistemic perspectives are fundamental for a given subject, i.e. there is no other perspective that she uses to determine the epistemic merits of that perspective (e.g. its rationality or its accuracy). A motivation for the existence of fundamental perspectives can be found in Field (2000). ${ }^{17}$ He claims that attributing an epistemic perspective to someone consist in making an idealization based on her behaviour. The issue is then determining which is the best idealization. On the one hand, one can adopt a view according to which there is a hierarchy of epistemic perspectives which ends up in a fundamental one. The alternative is attributing to the subject different perspectives of the same level, that she alternatively uses to evaluate each other. ${ }^{18}$ Field comments:

But there is an obvious weakness in an idealization of the latter sort: it is completely uninformative about what the agent does when the rules conflict. There is in fact some process that the agent will use to deal with such conflicts. Because this conflict-breaking process is such an important part of how the agent operates, it is natural to consider it a rule that the agent is following. If so, it would seem to be a basic rule, with the 'multiple rules' really just default rules that operate only when they don't come into conflict with other default rules. (Field, 2000, p. 390$)^{19}$

The second assumption, inspired on Lewis' discussion of inductive methods (Lewis, 1971), imposes a condition on reasonable epistemic perspectives. ${ }^{20}$ Lewis notices, in the first place, that in order to choose an inductive method, one needs to use an inductive method. This is because the choice of an inductive method has to be based on the estimated accuracy of such method, which can only be determined using an inductive method. Second, he claims that inductive methods can be either modest or immodest. An inductive method is immodest if it estimates that it is at least as good as any of its rivals at leading to truths and avoiding errors. This means that it doesn't recommend any method over itself. By contrast, a modest inductive method sometimes recommends some other methods over itself. Third, he argues that it is unreasonable to use a modest inductive method, for it cannot be coherently followed: suppose that inductive method

17 See also Lynch (2010) and Pittard (2019) for views that assume the existence of fundamental methods. The assumption that there are some epistemic methods that we treat as fundamental is also present in the literature on hinge epistemology (e.g. Ranalli (2018)). We leave discussion of this literature for future work.

18 An anonymous reviewer suggests a third possibility, namely that the subject treats different perspectives as fundamental in different contexts, depending on what best serves her interests. As we will see below, this is compatible with our view that steadfastness is sometimes rationally permitted, as long as it is granted that there are some contexts in which there can be peer disagreements involving epistemic perspectives that the subjects treat as fundamental.

19 Our use of 'fundamental' is equivalent to Field's use of 'basic' in this paragraph.

${ }^{20}$ To be sure, we do not claim that this is a sufficient condition but only a necessary one. 
A recommends believing $\mathrm{P}$, while inductive method $\mathrm{B}$ recommends believing $\neg \mathrm{P}$. If, in addition, A recommended following $\mathrm{B}$, then it would recommend, on the one hand, believing $\mathrm{P}$, and, on the other hand, believing $\neg \mathrm{P} .{ }^{21}$ For reasons analogous to Lewis', we maintain that fundamental epistemic perspectives are either modest or immodest, and that it is unreasonable to hold a modest fundamental epistemic perspective, since such a perspective could not be coherently followed.

Let's sum up our view on epistemic perspectives. Epistemic perspectives are methods for determining the rational attitude to hold towards any proposition given the available evidence, a set of theoretical values (hierarchically ordered according to the preferences of the subject) as well as different stances concerning the status of a given fact as evidence, the relative weight of various kinds of evidence and maybe some privileged epistemic goals. Some perspectives are fundamental for a subject, in the sense that there is no more basic epistemic perspective that she uses to assess that perspective's epistemic status. Moreover, since in order to determine the estimated accuracy or rationality of a certain perspective she needs to use a perspective, by Lewis' argument, reasonable fundamental epistemic perspectives are immodest.

\subsection{DiffERENT KindS OF DisagreEMENT}

Now that we have made the notion of an epistemic perspective a bit more precise we can make more fine grained distinctions concerning epistemic peerhood and peer disagreements. First, we distinguish strong and weak epistemic peers. Strong Epistemic Peers are Epistemic Peers (namely, they are evidential and cognitive equals) who share an epistemic perspective, which they apply in a similar way. Weak Epistemic Peers are Epistemic Peers who do not share their epistemic perspectives, or that do not apply their epistemic perspectives in a similar way. In parallel, there are at least two kinds of disagreement. Weak Peer Disagreements (WPD) are disagreements between strong epistemic peers, while Strong Peer Disagreements (SPD) are disagreements between weak epistemic peers.

As we saw in section 3, scientific disagreements are frequently resolved by exposing mistakes or inconsistencies in the way of interpreting the evidence or just by looking for new evidence. On our terminology, these are are instances of WPDs. We already noted that consideration of these cases suggests some sort of conciliatory attitude in scientists. By contrast, the scientific disagreements that we denominated WECs fall under the definition of SPD: they are due neither to cognitive failure nor to ignorance on the part of the subjects but to differences concerning their basic methods for determining which is the most rational hypothesis. In those cases, the dispute could emerge because scientists prioritize different theoretical values or epistemic goals, because they have different ways of weighting the evidence, distinct explanatory demands or different ways of employing their epistemic perspectives. In those cases, we will argue, to be steadfast is rationally permissible.

${ }^{21}$ Immodesty might also be problematic, for it seems that a method's self-recommendation is not epistemically significant. 


\subsection{An argument for steadfastness}

In order to argue for a steadfast view, let's reconsider the case we discussed in section 3 . There, we saw that EBMers and advocates of the Russo-Williamson thesis adopt different epistemic perspectives relative to different theoretical values and some preferred epistemic goals. Both views look like good candidates for fundamental epistemic perspectives. These views set different demands of explanation when it comes to reliably determining the existence of a causal relation, but there doesn't seem to be any shared meta-perspective that the parties in the discussion could use to determine which perspective is preferable. To setthe the issue, one should compare both views and see which one is better at determining causal relations. But in order to do that you need a perspective that establishes how stringent your demands should be for believing that a genuine causal relation has been spotted. This is exactly what EBM and the Russo-Williamson thesis are about. This suggests that it is not possible to settle this issue in a way that abstracts form the the perspectives involved. Thus, the disagreement between EBMers and defenders of mechanistic explanations can be thought of as a SPD involving fundamental perspectives, so that there is no meta-perspective that could be appealed to in order to determine empirically which of the perspectives in dispute is better.

We want to argue that SPDs involving fundamental epistemic perspectives such as that between EBMers and defenders of mechanistic views (fundamental SPDs) allow the parties in the dispute to rationally retain their attitudes, that is, they permit a steadfast reaction. To see why, we show that in SPDs the standard arguments in favor of conciliationism (from rationality and from accuracy, see section 2) can be blocked. Recall that we followed Lewis in arguing that reasonable epistemic perspectives are immodest, i.e. they always estimate that they are at least as accurate or rational as other incompatible ones, on pain of incoherence. This already suggests a tendency to prioritize one's epistemic perspective. Immodesty by itself does not suffice to secure a steadfast reaction, however. Even if each party's perspective is immodest, they could both appeal to a higher-level shared perspective to settle the disagreement. And in many cases they will just do that. However, when the disagreement is over their fundamental epistemic perspectives, there is no shared meta-perspective that they could use to resolve the conflict. This is what we saw in the disagreement between EBMers and defenders of mechanistic explanations, where the subjects could not approach the disagreement but from their own perspectives. Consequently, faced with such a disagreement they will evaluate the merits of their perspective as well as that of their opponent's perspective by using their own perspective.

Together, these two facts (the fundamental character of the perspective and its immodesty) support the conclusion that each subject can rationally retain her own epistemic perspective, and therefore her own belief on the matter. It follows from the fundamental character of the perspectives that each subject uses her own perspective in assessing which perspective is better. It follows from the immodesty of the perspectives that each perspective, if it is a reasonable one, estimates that it is at least as good as its alternatives. The latter means that either it estimates that it is at least equally accurate or rational to their alternatives, or that it is more accurate or rational than its alternatives. In the former case, the subject is obviously rational in maintaining her original attitude. In the latter case, however, it is also rationally permissible for the agent to retain her own perspective, and consequently, her own doxastic attitude, since adopting the rival's perspective would make no difference 
as to the accuracy or rationality of the subject's belief. Either way, we can conclude that it is rationally permissible for them to retain their original attitudes in the face of disagreement. $^{22,23}$

To better understand the way in which the conciliationist argument is blocked by the previous considerations, recall that both versions of the argument depended upon the principle of Independence. In section 2, we characterized evidence from peer disagreement as higher-order evidence, namely evidence that one's initial assessment of the evidence is on the wrong path. As we saw, according to the conciliationist argument higher-order evidence from peer disagreement can constitute a defeater for the subject's belief. Crucially, though, this is only in so far as Independence is in force. This principle states that one should assess the epistemic merits of one's opponent's attitude independently of the reasoning behind one's initial belief. However, if we are correct SPDs about fundamental epistemic perspectives show that this principle does not hold in general: in those cases, scientists cannot solve the disagreement by appealing to a shared background perspective, and they cannot judge the merits of the rival's view but from their own perspective. Thus, in assessing their rival's view scientists have some sort of epistemic blindspot: they cannot step out of their perspective and see things from a different one. ${ }^{24}$ Now, since both arguments for conciliationism require Independence, they are blocked by the previous considerations. ${ }^{25}$ In other words, higher-order evidence from peer disagreement has no defeating force in these cases.

The kind of evidence we have considered so far is not the only kind of higherorder evidence there is, however. Straßer et al. (2015) distinguish between two different kinds of higher-order evidence, content-based indices and form-based indices. The former concerns

22 Our account is compatible with the idea that it is possible to rationally change one's fundamental perspective based on non-epistemic reasons, like prudential or pragmatic reasons.

${ }^{23}$ Notice that, as defined, immodesty does not foreclose the possibility that a subject recognizes an incompatible epistemic perspective as equally accurate or rational to her own. Now, one might have doubts that this is reasonable. One could hold that a subject cannot rationally believe there are two (or more) equally rational fundamental epistemic perspectives, while rationally holding either. For example, by analogy with White's (2005) arguments, one could claim that if the subject recognized an incompatible perspective as equally rational to her own, then the choice about what perspective to adopt, and therefore about what to believe, would be arbitrary, and arbitrariness would preclude the agent from being epistemically rational. If this or some other argument to the same conclusion proved to be correct, immodesty would be stronger than we defined: an immodest epistemic perspective would estimate that it is more accurate or rational than its alternatives. This would make our argument stronger: steadfastness would not only be permitted in fundamental SPDs but required. However, since this idea is controversial and we do not need it to secure the desired conclusion (namely, that agents are rationally permitted to be steadfast in some scientific disagreements), we stick to the formulation given above.

24 Thus, our view could be understood as a normative argument for what Straßer et al. (2015) denominate the enstatic view, at least regarding cases where the perspectives under question are fundamental. According to the ecstatic view, in turn, scientists can go back and forth from different epistemic perspectives, judge things from the rival's perspective and recognize whether her view is rational.

25 Schoenfield (2014, p. 202) argues for a similar position in this regard: "This is just a fact about epistemic life that we have to live with: the methods that we use to evaluate evidence are not the sorts of things we can give independent justification for." We agree with the general idea, but we argue that this fact holds only for our fundamental methods, not for any method. 
the argumentative content of the dispute. This includes the kind of things we have already discussed: different preferences regarding epistemic values (e.g. simplicity over completeness), different methodological standards, etc. The latter, in turn, concerns structural properties of the controversy, like the length of the debate, the number of experts involved on each side of the disagreement and the expertise of the participants.

We already argued that in fundamental SPDs content-based indices do not defeat the subject's belief. What about form-based indices? According to Straßer et al., form-based indices signal that the views on both sides of the debate are the product of rational deliberation. Consequently, the parties involved have to be epistemically tolerant, that is, they should admit the opponent's view as potentially rational (although they consider it objectionable in important ways) while assuming the commitment to engage critically with the rival position and, eventually, to modify theirs, should it be required. Crucially, this is compatible with our view. As we discussed in section 2.2, our argument for steadfastness works within a synchronic, individual approach to epistemic rationality that focuses on attitudes like belief or credence. The argument for epistemic tolerance, in turn, is best understood within a diachronic, collective approach involving attitudes like endorsement or acceptance. It is coherent to deny, on the one hand, that form-based indices defeat the subject's belief in fundamental SPDs and maintain, on the other hand, that they require recognizing the rival's attitude as potentially rational. Thus, it is coherent to defend a steadfast view for fundamental SPDs while recognizing the need of epistemic tolerance in collective inquiry.

Now, there has been some discussion in the literature concerning fundamental disagreements. Lynch (2010) and Pittard (2019), for example, advocate views in the same spirit as ours. Both of them focus on disagreements over fundamental epistemic principles or epistemic starting points (what we have called strong disagreements). Their arguments, however, have different scope. Lynch argues that these disagreements are epistemically irresoluble. ${ }^{26}$ Roughly, the reason is that when it comes to disagreements over fundamental epistemic principles there is no epistemic reason that either party could offer to her opponent that does not presuppose the reliability of her own preferred principle. Hence, neither party is capable of putting forward reasons that the other party is able to recognize as epistemic reasons. For Lynch, discussions over fundamental principles are unavoidably epistemically circular. Lynch's view goes in the same direction as ours, but there are some substantive differences. Crucially, his argument does not differentiate between peer disagreements and disagreements between experts and non-experts, while our argument is intended to apply only to the former cases. Furthermore, Lynch's conclusion depends upon a notion of rational resolvability (Ranalli, 2018) that we have not discussed here, and about which we would like to remain neutral.

Pittard (2019) also provides an argument for a similar conclusion as ours, within a Bayesian framework. He maintains that the Equal Weight View requires Instrumentalism, the view that one should treat the output of one's cognitive system as readouts of a complex instrument. Instrumentalism requires that agents conditionalize on the evidence supplied by those readouts using her estimated reliability on the proposition and a prior credence that is rationally antecedent to the readout in question (Pittard, 2019, p. 13).

\footnotetext{
${ }^{26}$ He does not focus specifically on cases of peer disagreement, but his argument applies to those cases.
} 
However, he claims that agents cannot take an instrumentalist stance to all of their doxastic attitudes. When it comes to a fundamental view $p$, a so-called ur-prior, there is simply no prior probability on $p$ that is not informed by the agent's readouts on $p$. Furthermore, he maintains that imposing the additional condition that the estimation of one's own reliability on a fundamental matter be based only on considerations that are independent of the proposition under discussion (that is, a condition similar to Independence) leads to problems (Pittard, 2019, p. 18). He concludes that there is much less pressure to conciliate when it comes to fundamental issues than in 'superficial' disagreements. Pittard's argument goes in the same direction as ours. In this case, however, our argument is more general: since we do not assume a Bayesian framework, a specific way for conditionalizing on evidence or the thesis of Instrumentalism, we believe that our argument extends more easily to different epistemic frameworks.

To end up, we address a possible objection. The objection says that the argument we gave is unacceptably question-begging. It goes as follows: conciliationists arguably think that Conciliationism itself is part of our fundamental epistemic perspectives. If so, then it is not true that some SPDs are such that there is no higher-order epistemic perspective that could be used to settle the issue. We can always appeal to Conciliationism itself. To assume otherwise is to assume that Conciliationism is not part of our fundamental epistemic perspective, and that begs the question against Conciliationism.

Our answer is twofold. First, although some conciliationists might argue that Conciliationism itself is part of our fundamental epistemic perspectives, this is not essential to the view. There is nothing in principle incoherent about a conciliationist view that does not treat Conciliationism as part of our fundamental epistemic perspectives. If this is correct, the argument does not beg the question against conciliationism. Second, there are independent reasons to maintain that Conciliationism is not part of our fundamental epistemic perspective. Elga (2010) argues that a coherent fundamental inductive method cannot include Conciliationism, because it would be self-undermining in cases of disagreement over Conciliationism itself. While discussing Elga's view, Pittard (2015, p. 446) concurs: "Elga is right, I think, in maintaining that a coherent and reasonable inductive method cannot include a uniform conciliatory policy that applies to all disagreements, including disagreements over the policy itself. So any conciliationist who thought that a peer's credence should always be given equal weight, for example, stands refuted." In the same line, Reining (2016, p. 311) concedes that cases of peer disagreement over Conciliationism face the conciliationist with an epistemic dilemma, in which she is rationally required not to be conciliatory.

In answer to this problem, Pittard argues for a specific version of Conciliationism, Resolute Conciliationism, according to which the conciliatory rule is to be thought of as a default rule, that is, a rule that is mandatory unless one encounters evidence of its unreliability or it violates some rational requirement. Reining, for his part, argues for pro tanto Conciliationism, where peer disagreement is considered to be a reason for modifying one's attitude, but one that can be outweighed by other reasons. In both approaches, conciliationism should not be applied in every circumstances, hence the self-undermining problem is blocked. But to be sure, in neither of these accounts Conciliationism is part of a fundamental perspective, since it can be overruled in certain circumstances. 
Given all of this, we can say that although there could be a version of Conciliationism that regards it as part of our fundamental epistemic perspectives, this view is not essential to Conciliationism and it faces important challenges.

\section{Conclusion}

In this article, we analyzed a concrete case of scientific disagreement, namely that between EBMers and supporters of mechanistic reasoning. First, we motivated the intuition that this kind of scientific disagreements allow for a steadfast reaction. Then, we characterized this case as a disagreement between subjects with different fundamental epistemic perspectives. After identifying the main components of epistemic perspectives and laying out some reasonable assumptions about them, we introduced a distinction between weak and strong peer disagreements. Then, we provided a normative argument for the view that fundamental strong peer disagreements such as the one between EBMers and advocates of mechanistic reasoning allow for a steadfast reaction. In a nutshell, the argument is that, given the immodest nature of fundamental epistemic perspectives, Independence has not bite in those cases, so typical arguments for conciliation are blocked.

\section{Acknowledgments}

We would like to express our gratitude to two anonymous referees of THEORIA for their critical remarks on a previous version of this paper. Their comments contributed to the improvement of the arguments presented here.

\section{REFERENCES}

Ballantyne, N., \& Coffman, E. J. (2012). Conciliationism and uniqueness. Australasian Journal of Philosophy, 90(4), 657-670. doi: https://doi.org/10.1080/00048402.2011.627926

Borge, B. (2021). Disagreement about scientific ontology. Journal for General Philosophy of Science, 1-17. doi: https://doi.org/10.1007/s10838-020-09542-2

Boucher, S. C. (2014). What is a philosophical stance? paradigms, policies and perspectives. Synthese, 191(10), 2315-2332. doi: https://doi.org/10.1007/ s11229-014-0400-y

Burns, P. B., Rohrich, R. J., \& Chung, K. C. (2011). The levels of evidence and their role in evidence-based medicine. Plastic and reconstructive surgery, 128(1), 305. doi: https://doi.org/10.1097/ PRS.0b013e318219c171

Carter, J. A. (2014). Disagreement, relativism and doxastic revision. Erkenntnis, 79(1), 155-172. doi: https://doi.org/10.1007/s10670-013-9450-7

Cartwright, N. (2011). A philosopher's view of the long road from rcts to effectiveness. The Lancet, 377(9775), 1400-1401. doi: https://doi.org/10.1016/ S0140-6736(11)60563-1

Cartwright, N., \& Munro, E. (2010). The limitations of randomized controlled trials in predicting effectiveness. Journal of evaluation in clinical practice, 6(2), 260-266. doi: https://doi.org/10.1111/j.13652753.2010.01382.x

Christensen, D. (2009). Disagreement as evidence: The epistemology of controversy. Philosophy Compass, 4(5), 756-767. doi: https://doi.org/10.1111/ j.1747-9991.2009.00237.x 
Christensen, D. (2010). Higher-order evidence. Philosophy and Phenomenological Research, 81(1), 185-215. doi: https://doi.org/10.1111/j.1933-1592.2010.00366.x

Christensen, D. (2016). Conciliation, uniqueness and rational toxicity. Noûs, 50(3), 584-603. doi: https:// doi.org/10.1111/nous.12077

Cohen, S. (2013). A defense of the (almost) equal weight view. In J. Lackey \& D. Christensen (Eds.), The epistemology of disagreement: New essays (pp. 98-117). Oxford: Oxford University Press.

Craver, C., \& Tabery, J. (2015). Mechanisms in science. The Stanford encyclopedia of philosophy. Retrieved from https://plato.stanford.edu/entries/ science-mechanisms/

De Cruz, H., \& De Smedt, J. (2013). The value of epistemic disagreement in scientific practice. the case of homo floresiensis. Studies in History and Philosophy of Science, 44(2), 169-177. doi: https://doi. org/10.1016/j.shpsa.2013.02.002

De Donato Rodríguez, X., \& Zamora Bonilla, J. (2014). Scientific controversies and the ethics of arguing and belief in the face of rational disagreement. Argumentation, 28(1), 39-65. doi: https://doi. org/10.1007/s10503-013-9300-4

Douven, I. (2009). Uniqueness revisited. American Philosophical Quarterly, 46(4), 347-361. doi: https:// www.jstor.org/stable/40606911

Elga, A. (2010). How to disagree about how to disagree. In R. Feldman \& T. Warfield (Eds.), Disagreement (pp. 175-187). Oxford: Oxford University Press.

Elgin, C. (2010). Persistent disagreement. In R. Feldman \& T. Warfield (Eds.), Disagreement (pp. 53-68). Oxford: Oxford University Press.

Field, H. (2000). Apriority as an evaluative notion. In P. A. Boghossian \& C. Peacocke (Eds.), New essays on the a priori (pp. 17-149). Oxford: Oxford University Press.

Fleisher, W. (2020). How to endorse conciliationism. Synthese. doi: https://doi.org/10.1007/s11229-020$02695-\mathrm{z}$

Gillies, D. A. (2010). The russo-williamson thesis and the question of whether smoking causes heart disease. In P. M. Illari, F. Russo, \& J. Williamson (Eds.), Causality in the sciences (pp. 110-125). Oxford: Oxford University Press.

Glennan, S. S. (1997). Probable causes and the distinction between subjective and objective chance. Nôus, 31(4), 496-519.

Group, E.-B. M. W. (1992). Evidence-based medicine: A new approach to teaching the practice of medicine. JAMA, 17(268), 2420-2425. doi: https://doi.org/10.1001/jama.1992.03490170092032

Hanson, N. R. (1958). Patterns of discovery: An inquiry into the conceptual foundations of science (Vol. 251). Cambridge University Press.

Howick, J. H. (2011). The philosophy of evidence-based medicine. Chichester: Wiley-Blackwell. doi: https:// doi.org/10.1002/9781444342673

Joyce, J. M. (1998). A nonpragmatic vindication of probabilism. Philosophy of science, 65(4), 575-603. doi: https://www.jstor.org/stable/188574

Junges, A. L. (2013). Desacordo racional e controvérsia científica. Scientiae Studia, 11(3), 613-635. doi: https://doi.org/10.1590/S1678-31662013000300008

Kelly, T. (2010). Peer disagreement and higher order evidence. In R. Feldman \& T. Warfield (Eds.), Disagreement (pp. 111-174). Oxford: Oxford University Press.

Kelly, T. (2013). Evidence can be permissive. In M. Steup, J. Turri, \& E. Sosa (Eds.), Contemporary debates in epistemology (pp. 298-312). Malden, MA: Blackwell.

Kelp, C., \& Douven, I. (2012). Sustaining a rational disagreement. In H. de Regt, S. Hartmann, \& S. Okasha (Eds.), Epsa philosophy of science: Amsterdam 2009 (Vol. 1, pp. 101-110). Dordrecht: Springer. doi: https://doi.org/10.1007/978-94-007-2404-4 10

Kornblith, H. (2010). Belief in the face of controversy. In R. Feldman \& T. Warfield (Eds.), Disagreement (pp. 29-52). Oxford: Oxford University Press.

Kuhn, T. S. (1962). The structure of scientific revolutions. Chicago: University of Chicago press. 
La Caze, A. (2011). The role of basic science in evidence-based medicine. Biology \& Philosophy, 26(1), 81-98. doi: https://doi.org/10.1007/s10539-010-9231-5

Lacey, H. (2015). 'Holding' and 'endorsing' claims in the course of scientific activities. Studies in History and Philosophy of Science Part A, 53, 89-95. doi: https://doi.org/10.1016/j.shpsa.2015.05.009

Lackey, J. (2010). A justificationist view of disagreement's epistemic significance. In A. Millar, A. Haddock, \& D. Pritchard (Eds.), Social epistemology (pp. 298-235). Oxford: Oxford University Press.

Lackey, J. (2013). Disagreement and belief dependence: Why numbers matter. In D. Christensen \& J. Lackey (Eds.), The epistemology of disagreement: New essays (pp. 243-268). Oxford: Oxford University Press.

Lasonen-Aarnio, M. (2014). Higher-order evidence and the limits of defeat. Philosophy and Phenomenological Research, 88(2), 314-345. doi: https://doi.org/10.1111/phpr.12090

Laudan, L., \& Leplin, J. (1991). Empirical equivalence and underdetermination. The journal of philosophy, 88(9), 449-472. doi: https://doi.org/10.2307/2026601

Lee, M. (2013). Conciliationism without uniqueness. Grazer Philosophische Studien, 88(1), 161-188. doi: https://doi.org/10.1163/9789401210508 009

Lewis, D. (1971). Immodest inductive methods. Philosophy of Science, 38(1), 54-63. doi: https://www.jstor. org/stable/186761

Lichtenstein, E. I. (2020). (Mis)understanding scientific disagreement: Success versus pursuit-worthiness in theory choice. Studies in History and Philosophy of Science Part A. doi: https://doi.org/10.1016/j. shpsa.2020.10.005

Lugg, A. (1980). Theory choice and resistance to change. Philosophy of Science, 47(2), 227-243.

Lynch, M. P. (2010). Epistemic circularity and epistemic incommensurability. In A. Millar, A. Haddock, \& D. Pritchard (Eds.), Social epistemology (pp. 262-277). Oxford: Oxford University Press.

Pittard, J. (2015). Resolute conciliationism. The Philosophical Quarterly, 65(260), 442-463. doi: https:// doi.org/10.1093/pq/pqv022

Pittard, J. (2019). Fundamental disagreements and the limits of instrumentalism. Synthese, 196(12), 50095038. doi: https://doi.org/10.1007/s11229-018-1691-1

Ranalli, C. (2018). Deep disagreement and hinge epistemology. Synthese, 1-33. doi: https://doi. org/10.1007/s11229-018-01956-2

Reining, S. (2016). On the supposed dilemma of conciliationism. Episteme, 13(3), 305-328. doi: https://doi. org/10.1017/epi.2015.47

Russo, F., \& Williamson, J. (2007). Interpreting causality in the health sciences. International studies in the philosophy of science, 21(2), 157-170. doi: https://doi.org/10.1080/02698590701498084

Sackett, D. L., Straus, S. E., Richardson, W. S., Rosenberg, W., \& Haynes, R. B. (2000). Evidence-based medicine: How to practice and teach ebm. Churchill Livingstone.

Salmon, M. (2000). Art or science? a controversy about the evidence for cannibalism. In P. Machamer, M. Pera, \& A. Balta (Eds.), Scientific controversies: Philosophical and historical perspectives (pp. 199-212). Oxford: Oxford University Press.

Schoenfield, M. (2014). Permission to believe: Why permissivism is true and what it tells us about irrelevant influences on belief. Noûs, 48(2), 193-218. doi: https://doi.org/10.1111/nous.12006

Šešelja, D. (2019). Some lessons from simulations of scientific disagreements. Synthese, 1-16. doi: https://doi. org/10.1007/s11229-019-02182-0

Solomon, M. (1992). Scientific rationality and human reasoning. Philosophy of Science, 3(59), 439-455. doi: https://doi.org/10.1086/289680

Sosa, E. (2010). The epistemology of disagreement. In A. Millar, A. Haddock, \& D. Pritchard (Eds.), Social epistemology (pp. 278-296). Oxford: Oxford University Press.

Straßer, C., Šešelja, D., \& Wieland, J. W. (2015). Withstanding tensions: Scientific disagreement and epistemic tolerance. In E. Ippoliti (Ed.), Heuristic reasoning. studies in applied philosophy, epistemology and rational ethics (Vol. 16, pp. 113-146). Cham: Springer. doi: https://doi.org/10.1007/978-3-319$09159-46$ 
Timmermans, S., \& Berg, M. (2003). The gold standard: the challenge of evidence-based medicine. Philadelphia: Temple University Press.

Weinberger, N., \& Bradley, S. (2020). Making sense of non-factual disagreement in science. Studies in History and Philosophy of Science Part A, 83, 36-43. doi: https://doi.org/10.1016/j.shpsa.2020.01.004

White, R. (2005). Epistemic permissiveness. Philosophical Perspectives, 9, 445-459. doi: https://doi. org/10.1111/j.1520-8583.2005.00069.x

Worrall, J. (2002). What evidence in evidence-based medicine? Philosophy of science, 69(3), 316-330.

Worrall, J. (2007a). Evidence in medicine and evidence-based medicine. Philosophy Compass, 2(6), 9811022. doi: https://doi.org/10.1111/j.1747-9991.2007.00106.x

Worrall, J. (2007b). Why there's no cause to randomize. The British Journal for the Philosophy of Science, 58(3), 451-488. doi: https://www.jstor.org/stable/30115184

BRUNO BORGE is Associate Professor of Philosophy of Science at the University of Buenos Aires, and Assistant Researcher at the National Council of Scientific and Technical Research (CONICET). He works in the metaphysics and epistemology of science. His research interests include scientific realism, laws of nature, fundamentality, scientific representation, and scientific disagreement.

ADDRESS: Faculty of Philosophy and Literature, University of Buenos Aires, 480 Puan Street, Buenos Aires, C1406CQJ, Argentina. E-mail: brunojborge@gmail.com

Website: https://uba.academia.edu/BrunoBorg ORCID: 0000-0002-1755-9690

NICOLÁs LO GUERCIO is a Postdoctoral fellow at the National Agency for the Promotion of Science and Technology and a member of the Institute of Philosophical Investigations, Argentinian Society for Philosophical Analysis. He works in philosophy of language and epistemology, especially in the semantics/ pragmatics divide, proper names, expressive meaning and slurs, social epistemology, peer disagreement and higher-order evidence.

ADDRESS: Institute of Philosophical Research (SADAF/CONICET), 642 Bulnes Street, Buenos Aires, C1176ABL, Argentina. E-mail: nicolasloguercio@gmail.com ORCID: 0000-0003-4663-9080 